\title{
Commentary
}

\section{Acute Ischaemic Stroke in Infective Endocarditis: Pathophysiology and Clinical Outcomes in Patients Treated with Reperfusion Therapy}

\author{
Rohan Maheshwari ${ }^{1,2}$, Daniel Wardman ${ }^{2,3,4}$, Dennis John Cordato ${ }^{2,3,4}$ and \\ Sonu Menachem Maimonides Bhaskar 1,2,3,4,5,*(D) \\ 1 Neurovascular Imaging Laboratory, Clinical Sciences Stream, Ingham Institute for Applied Medical Research, \\ Sydney, NSW 2170, Australia; rohan.maheshwari@student.unsw.edu.au \\ 2 South Western Sydney Clinical School, The University of New South Wales (UNSW), Sydney, NSW 2170, \\ Australia; Daniel.Wardman@health.nsw.gov.au (D.W.); Dennis.Cordato@health.nsw.gov.au (D.J.C.) \\ 3 Department of Neurology and Neurophysiology, Liverpool Hospital, South Western Sydney Local Health \\ District (SWSLHD), Sydney, NSW 2170, Australia \\ 4 Stroke and Neurology Research Group, Ingham Institute for Applied Medical Research, Sydney, NSW 2170, \\ Australia \\ 5 NSW Brain Clot Bank, NSW Health Pathology, Sydney, NSW 2170, Australia \\ * Correspondence: Sonu.Bhaskar@reprogramglobal.org; Tel.: +61-(02)-873-89179; Fax: +61-(02)-8738-3648
}

Citation: Maheshwari, R.; Wardman, D.; Cordato, D.J.; Bhaskar, S.M.M. Acute Ischaemic Stroke in Infective Endocarditis: Pathophysiology and Clinical Outcomes in Patients Treated with Reperfusion Therapy. Immuno 2021, 1, 347-359. https://doi.org/ 10.3390/immuno1040023

Academic Editor: Jonghwan Park

Received: 11 August 2021

Accepted: 17 September 2021

Published: 24 September 2021

Publisher's Note: MDPI stays neutral with regard to jurisdictional claims in published maps and institutional affiliations.

Copyright: (c) 2021 by the authors. Licensee MDPI, Basel, Switzerland. This article is an open access article distributed under the terms and conditions of the Creative Commons Attribution (CC BY) license (https:// creativecommons.org/licenses/by/ $4.0 /)$.

\begin{abstract}
Infective endocarditis in the setting of acute stroke poses a clinical challenge given the high mortality and morbidity associated with the condition. The pathophysiological mechanisms including clinical and imaging biomarkers that can provide insights into clinical trajectories of such patients are of immense interest. The current paper aims to provide a comprehensive overview of acute stroke with infective endocarditis and provide insights into various clinical factors mediating outcomes and therapeutic strategies, specifically in the setting of reperfusion therapy. Prognostic and therapeutic pathways to potentially improve functional outcomes in these patients are also discussed.
\end{abstract}

Keywords: stroke; infective endocarditis; reperfusion therapy; clinical outcomes; prognosis; cerebrovascular disease; thrombolysis; thrombectomy

\section{Main Messages}

- Management of acute ischaemic stroke patients with presumed or confirmed IE is challenging and treatment guidelines are far from optimal due to limited evidence.

- A comprehensive overview of acute stroke in the background of infective endocarditis is provided.

- Various clinical factors mediating outcomes and therapeutic strategies, specifically in the setting of reperfusion therapy, are also discussed.

\section{Introduction}

Stroke is a leading cause of mortality and morbidity worldwide [1]. Infective endocarditis (IE) in the setting of acute ischaemic stroke (AIS) may complicate treatment in AIS. Patients with IE may present with a neurovascular emergency such as AIS, haemorrhage or mycotic aneurysm [2]. Previous studies have reported mortality rates as high as 55-58\% in IE secondary to stroke [3,4]. IE is increasingly involving elderly patients: more than one-third of patients in Western nations are now beyond the age of 70 [5], with lower surgical treatment rates and a high mortality rate being the noticeable characteristics [6]. Moreover, reperfusion therapies are often less efficacious in these patients [7]. The data on risk factors and prognostic determinants of short-term and long-term clinical outcomes in patients with IE, especially those with comorbid stroke, is very limited $[3,8,9]$. This article aims to provide an overview of the pathophysiology and epidemiology of IE and stroke and outcomes in AIS patients with a background in IE. 


\section{Epidemiology of Infective Endocarditis}

Whilst the burden of IE globally ranges between 1.5-11.6 cases per 100,000 people, IE remains a serious disease with a high five-year mortality rate of $40 \%$ [10]. In high-income countries, degenerative valve disease, prosthetic valves and staphylococcus accounted for the majority of IE cases with recent increases in nosocomial IE [11]. In the state of New South Wales in Australia, between 2000-2006, the most frequent organism causing IE was staphylococcus aureus (32\%) with a non-rheumatic valvular disease-causing $20 \%$ of IE and rheumatic valvular disease accounting for only $10 \%$. Furthermore, healthcare-associated IE occurred in 30\% of cases [12]. A recent review in Eastern China found 30.5\% of IE cases were due to degenerative valve disease with a mean age of 47.8 years [13]. In contrast, in low-income countries, the majority of IE cases occur secondary to streptococci infection and rheumatic heart disease with patients being younger [11]. A 10-year retrospective study from Tunisia found rheumatic heart disease was responsible for $45.2 \%$ of native valve IE cases with a mean patient age of 32.4 [14], whilst a 2006 Argentinian national survey reported streptococci as the most frequent IE pathogen (27\%) [15].

\section{Aetiology of Infective Endocarditis}

The large majority of IE cases are caused by gram-positive bacteria, with staphylococcus aureus responsible for $44 \%$ of cases in a prospective cohort study of over 3000 patients [16]. Other causes of gram-positive IE included coagulase-negative staphylococci (e.g., staphylococcus epidermis), streptococcus bovis, Streptococcus viridans and enterococci [17]. IE predisposing conditions include native valve predisposition (32\%), such as degenerative valve disease (e.g., mitral or aortic valve regurgitation), history of invasive procedures in the previous 60 days $(27 \%)$, congenital heart disease $(12 \%)$, having an endocavitary device $(11 \%)$, intravenous drug use (10\%) and chronic intravenous access (9\%) [17]. Prosthetic valve IE $(21 \%)$ occurs due to predisposition to an increased risk of turbulent blood flow and thrombosis formation $[17,18]$.

\section{Infective Endocarditis Risk Factors and Pathophysiology}

IE develops in patients with prosthetic valves, implanted cardiac devices (e.g., pacemaker), or native valve damage creating foreign non-endothelialised surfaces. Disruption to the endothelial surface increases the risk of turbulent blood flow. Subsequent platelet and fibrin deposition form thrombotic vegetation(s), promoting bacterial adhesion [16,19]. Native valve abnormalities include congenital heart disease, rheumatic heart disease, mitral valve prolapse, hypertrophic cardiomyopathy or bicuspid/calcific aortic valves [19]. The likelihood of bacterial adhesion is greater in patients with a higher risk of bacteria entering their bloodstream. These patients include intravenous drug users, those on immunosuppressive medications (e.g., cancer patients), receiving a recent antibiotic course, having a recent dental procedure or open wounds and having indwelling catheters (e.g., haemodialysis) or intravenous lines [16]. Once bacteria adhere to the valve, they promote platelet, neutrophil and macrophage aggregation and the activation of the clotting cascade, promoting the proliferation of infectious thrombotic vegetation, which protects the embedded bacteria [19]. The pathogenesis of IE is summarised in Figure 1. 


\section{Risk Factors}

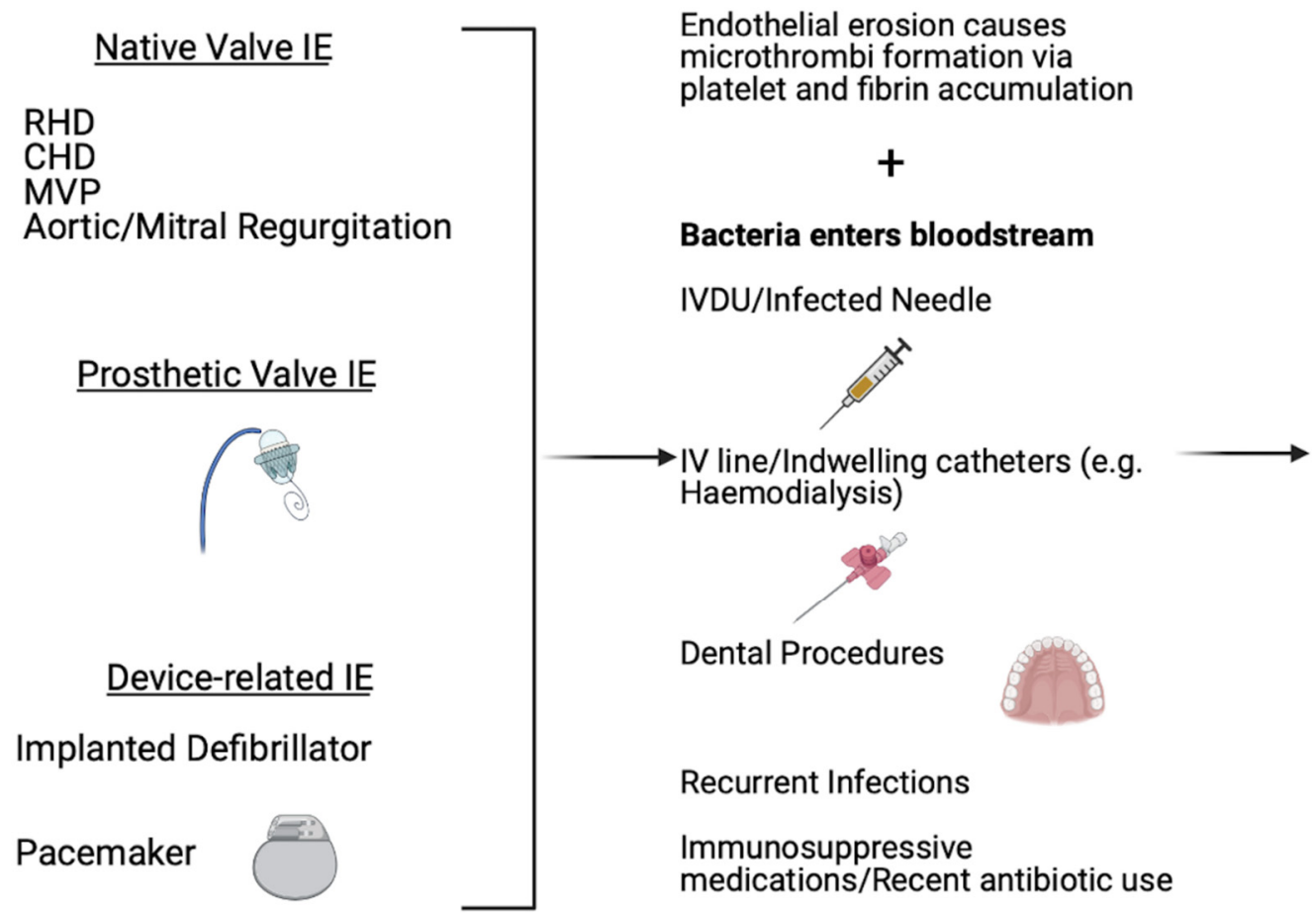

\section{Pathogenesis}

\author{
Bacteria adheres to \\ damaged valve or \\ artificial \\ valve/device
}

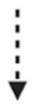

Bacteria proliferates

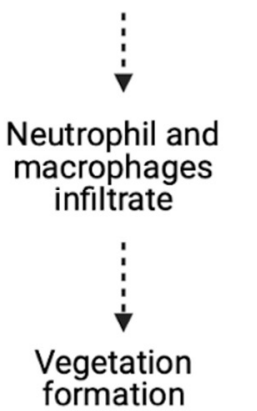

Figure 1. Risk factors and pathogenesis of infective endocarditis, Abbreviations: IE: Infective endocarditis; RHD: Rheumatic heart disease; CHD: Congenital heart disease; MVP: Mitral valve prolapse; IVDU: Intravenous drug user; IV: Intravenous.

\section{Epidemiology of Stroke}

Stroke is defined as rapidly developing signs indicating a focal or global disturbance of cerebral function occurring due to vascular interruption and lasting longer than $24 \mathrm{~h}$ (unless interrupted by death) [20]. Stroke is classified as either ischaemic or haemorrhagic due to the occlusion or rupture, respectively, of a blood vessel [20]. Stroke affects 13.7 million people and causes 5.5 million deaths annually worldwide making it the second leading cause of death worldwide [1]. The global disability-adjusted life-years and mortality for AIS have decreased relatively over the 1990-2013 period by $21.2 \%$ and $19.6 \%$, respectively, whilst global prevalence has increased relatively by $0.024 \%$ [21]. Reductions in stroke mortality and consequent increase in prevalence may have occurred due to improved detection, management and prevention strategies [1].

\section{Risk Factors for Stroke}

Risk factors for AIS are classified as either non-modifiable or modifiable [1]. 91.5\% of risk factors attributable to AIS are modifiable including hypertension $(>160 / 90 \mathrm{mmHg})$, sedentary lifestyle, hypercholesterolaemia, diabetes, smoking, high alcohol consumption, obesity (high waist-to-hip ratio) and cardiac disease (e.g., atrial fibrillation or past myocardial infarctions) [1]. Amongst these, hypertension is attributable to $60-70 \%$ of AIS and increases the risk of AIS by over three times [1,21]. Non-modifiable risk factors include age, gender, and genetics. For every decade after 55 years of age, the risk of stroke doubles, primarily due to increased exposure to risk factors [21]. Men have higher age-specific stroke rates and experience strokes at a younger age [21]. Finally, genome-wide analysis has found the heritability of AIS is approximately $37.9 \%$ [1].

\section{Pathophysiology of Acute Ischaemic Stroke}

The brain receives $20 \%$ of total cardiac output at rest and is extremely sensitive to ischaemia [22]. AIS occludes blood supply and the resultant reduction in delivery of 
oxygen and glucose causes inadequate adenosine triphosphate production within neurons. This results in the dysfunction of the sodium-potassium pump, an influx of calcium ions and resultant cellular swelling. The increase in intracellular calcium and lack of oxygen can cause the release of pro-inflammatory cytokines [22]. These generate reactive oxygen species whilst also causing protein misfolding, cytoskeleton breakdown and necrosis. Reactive oxygen species cause mitochondrial injury and cytochrome $c$ release, which begins a cascade resulting in apoptosis [1]. Initially, the greatest region of hypoperfusion causing irreversible infarction is the ischaemic core. However, the regions with less hypoperfusion that are functionally impaired but structurally intact represent the ischaemic penumbra and its salvage remains the focus of AIS therapy $[1,23]$.

\section{Aetiology of Stroke}

AIS accounts for $80-85 \%$ of all strokes and is sub-classified by differing aetiologies [20]. These include large artery thrombotic strokes, small-vessel lacunar strokes, cardiogenic embolic strokes (e.g., IE or atrial fibrillation), other causes (e.g., coagulation disorders) or undetermined causes [24].

\section{Pathophysiology of Acute Ischaemic Stroke in the setting of Infective Endocarditis}

Stroke in the setting of IE may be caused by embolization of endocardial vegetations followed by blockage of an intracerebral artery (Figures 1 and 2) $[25,26]$. The thrombus in acute IE can be caused by the invading organism (e.g., S. aureus) (spontaneous bacteraemia) or by valvular damage resulting from invasive procedures such as intravenous catheters or pacing wires [27-29]. Staphylococcus aureus can infiltrate endothelial cells, also called endotheliosis, and amplify the expression of adhesion molecules and procoagulant function on the cellular surface [29]. When bacteria colonise the surface of the vegetation, the process of platelet aggregation and fibrin buildup accelerates. As the bacteria proliferate, they are shielded from neutrophils as well as other host immunity by expanding layers of platelets and thrombin. Because of the nutrient scarcity, organisms at the deeper levels of vegetation hibernate, making them less vulnerable to bactericidal antimicrobials that infringe the bacterial cell membrane production. Besides, embolisation to cerebral or meningeal arteries can also cause meningitis or intracerebral abscess.

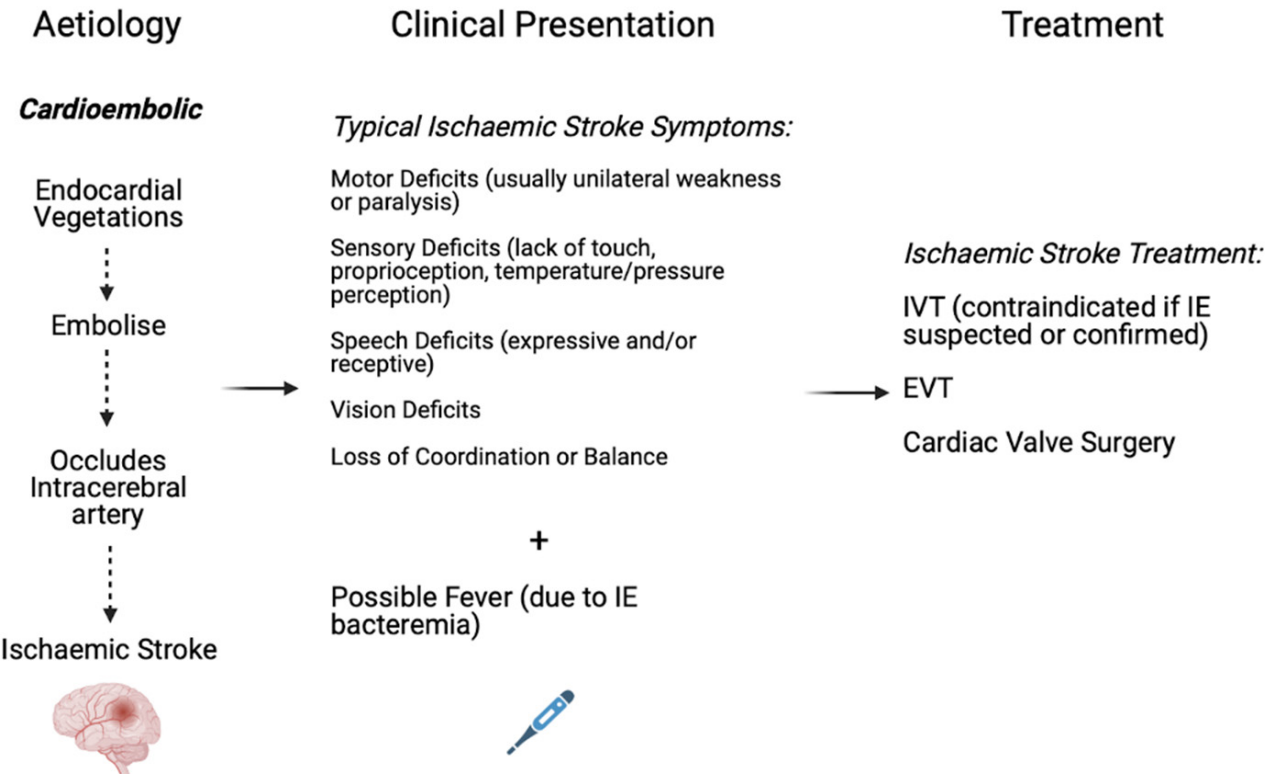

Figure 2. Aetiology, presentation, and treatment of acute ischaemic stroke secondary to infective endocarditis. Abbreviations: IE; Infective endocarditis; IVT: Intravenous thrombolysis; EVT: Endovascular thrombectomy. 


\section{Aetiology of Acute Ischaemic Stroke in the Setting of Infective Endocarditis}

Neurological complications in the setting of IE occurs in $25-70 \%$ of cases; however, AIS is the most common complication, manifesting in up to $40 \%$ of these patients [10,30]. Whilst IE is a relatively uncommon stroke risk factor due to a low global prevalence and causes less than $10 \%$ of all cardioembolic strokes, there is a high magnitude of association between IE and consequent stroke [31]. Further, embolic events secondary to IE have a 50\% chance of recurrence [26]. Stroke is most common in the early stages of IE and can be its presenting symptom.

In IE, specific factors that increase the risk of AIS include prior strokes, staphylococcus infection, vegetations on the mitral valve, especially the anterior leaflet, multivalvular vegetations, valvular abscesses and vegetations larger than 10 millimetres in length [32-34]. Staphylococcus infection $(\mathrm{HR}=2.0)$, mitral valve vegetations $(\mathrm{HR}=2.2)$ and valvular abscesses (HR $=2.7)$ all increase the risk of AIS by equal to or more than double [33]. One study found a $57 \%$ risk of emboli with vegetations above 10 millimetres in length compared to a $22 \%$ risk of emboli with vegetations below 10 millimetres in length [35]. Furthermore, there was a $48 \%$ risk of an embolism if the vegetation was mobile compared to $9 \%$ if it was fixed; however, these results closely correlated to the size of vegetations since larger vegetations were more likely to be mobile [35]. Larger and more mobile vegetations heighten the risk of AIS in IE patients due to the greater likelihood of vegetations fragmenting and embolising [35]. While no definite conclusions have been elucidated, staphylococcus infection could lead to larger vegetations and greater tissue destruction at the valve causing an increased risk of AIS [33]. Similarly, hypotheses exist that the greater shear stress around the mitral valve allows larger vegetations to form and increase the likelihood of emboli fragmenting and occluding an intracerebral artery [33]. Future studies should be aimed at the impact these risk factors in IE have upon the severity of stroke.

In IE, cardioembolic AIS occurs from the fragmentation of endocardial vegetations and subsequent occlusion of an intracerebral artery [36]. Potential bleeding into the infarct can cause haemorrhagic transformation (HT) [26]. The presentation of AIS in IE is similar to other ischaemic strokes; however, there may be the presence of fever due to the bacterial nature of IE [36]. Whilst intravenous thrombolysis (IVT) is contraindicated in the setting of IE, it is often administered due to IE diagnosis occurring later [7]. The mainstay treatment method includes endovascular thrombectomy (EVT) [7], whilst cardiac valve surgery is considered to prevent further neurological complications in the setting of IE alongside reducing mortality rates [37]. A schematic summarising the aetiology, presentation, and treatment of AIS in IE patients is displayed in Figure 2.

\section{Clinical Outcomes of Acute Ischaemic Stroke in Infective Endocarditis}

The outcomes of AIS due to IE include cerebral complications such as HT, meningitis, mycotic aneurysms and recurrent strokes [2]. Thuny et al. [38] found AIS was a strong predictor of five-year mortality ( $\mathrm{HR}=1.7 ; 95 \% \mathrm{CI} 1.09-2.43 ; p=0.02)$ in IE patients compared to patients not experiencing any cerebrovascular complication (CVC) (38\% vs. $31 \%$ ) whereas silent cerebral embolism or transient ischaemic attack (TIA) had a similar risk of mortality as no CVC [38]. Conducting valvular surgery for AIS influenced outcomes as $13.8 \%$ of AIS patients receiving surgery experienced five-year mortality compared to $66.7 \%$ of AIS patients receiving conservative medical treatment [38]. Furthermore, it is noted that IE outcomes are influenced by multiple IE aetiology factors with CVC occurring most frequently with mitral valve IE (58\%) and staphylococcus infection (28\%) [38].

The incidence of neurological complications, such as AIS, secondary to IE has been increasing gradually [3]. Whilst speculative, this may be due to an increasing number of invasive procedures leading to transient bacteraemia and gradual increases in high-risk populations, such as the elderly, diabetics and patients on haemodialysis or with prosthetic cardiac valves [3]. However, initiation of antibiotics is a preventative method for CVC secondary to IE with one study reporting $25 \%$ of IE patients not receiving antibiotics experienced CVC compared to $6 \%$ of those receiving antibiotic therapy [38]. Further, 
antimicrobial therapy should be implemented post-stroke in IE patients to prevent CVC recurrence [25].

\section{Reperfusion Therapy in Acute Ischaemic Stroke Patients with Infective Endocarditis}

Reperfusion therapy, via IVT and/or EVT, is the mainstay treatment available for AIS $[7,39]$. Whilst the factors mediating outcomes of reperfusion therapy in AIS have been well documented [40-47], our understanding of such clinical, imaging and systems variables in the setting of IE remains sub-optimal. Current guidelines for AIS recommend the use of IVT before EVT if presentation occurs within $4.5 \mathrm{~h}$ of symptom onset [48]. This does not apply in the setting of IE due to the substantial risk of haemorrhage, although IE diagnosis is difficult to achieve in this time period and thus sometimes leads to IVT being administered [7]. However, EVT treatment is associated with approximately 50\% of patients achieving a good functional outcome (modified Rankin Scale (mRS) score 0-2) at three months [49]. A systematic review found the risk of intracranial haemorrhage (ICH) was 4.14 times higher in AIS patients with IE receiving IVT compared to EVT alone [7]. Furthermore, in AIS patients with IE, a 1.85 times higher likelihood of achieving a good functional outcome (mRS 0-2) existed if patients received EVT compared to IVT [7]. However, this systematic review included several small sample-sized, low-quality studies including case reports and series, and in total analysed less than 50 patients. Further, publication bias likely exists due to the majority of patients undergoing EVT having a diagnosis of IE before treatment and potentially receiving antibiotics which may mediate outcomes due to emboli being smaller whilst all patients undergoing IVT had not yet been diagnosed with IE [7].

A similar systematic review and case series publication investigating AIS in IE patients found ICH occurred in $63 \%$ of patients receiving IVT; however, in only $18 \%$ of patients receiving EVT [50]. Dramatic neurological recovery, defined by a 10 point or greater decrease in the National Institute of Health Stroke Scale (NIHSS) score or a 0-1 NIHSS score at $24 \mathrm{~h}$ post-therapy, occurred in $58 \%$ of patients receiving EVT compared to $32 \%$ of IVT treated patients. Furthermore, $62 \%$ of EVT patients achieved a good functional outcome (mRS 0-2) compared to $37 \%$ of IVT patients at 90 days. Whilst this study included a detailed description of patient characteristics, it included older endovascular methods and devices reducing the generalisability of the results. Also, reporting bias exists due to the inclusion of several case reports and series, which sometimes did not include justifications for treatment choice or reports on ICH [50]. Further, in both systematic reviews, outcomes were not segregated by the exact thrombolysis agent or thrombectomy method utilised.

A large retrospective analysis of a nationwide inpatient sample over eight years found IE patients experiencing AIS receiving IVT demonstrated significantly lower rates of favourable outcomes and higher rates of post-thrombolytic ICH compared to AIS patients without IE [51]. However, this study did not include results on mortality and the exact agent utilised for IVT in every case was unknown. Moreover, the severity of neurological deficits and baseline functional status of patients was not assessed [51]. The IE cohort possibly had more severe pre-existing disabilities, reducing the validity of results obtained from this retrospective analysis. A six patient case series investigating EVT as a treatment modality reported no ICH post-EVT, while four of the six patients experienced dramatic early recovery post-EVT [52]. However, due to the low sample size, the generalisability of these results is debatable. Overall, our understanding of the best treatment options in AIS patients on the background of IE is suboptimal due to the lack of randomised control trials and studies with large sample sizes [7]. The following outcome results along with other studies' results are summarised in Table 1. 
Table 1. Outcomes of acute ischaemic stroke in patients with and without infective endocarditis.

\begin{tabular}{|c|c|c|c|c|c|c|}
\hline & \multicolumn{3}{|c|}{ AIS with a History of IE } & \multicolumn{3}{|c|}{ AIS without a History of IE } \\
\hline & $\begin{array}{l}\text { IVT } \\
\text { Only }\end{array}$ & EVT Only & IVT + EVT & IVT Only & EVT Only & IVT + EVT \\
\hline $\begin{array}{l}\text { Mortality } \\
(\mathrm{mRS}=6 \text { at } \\
\text { three months } \\
\text { post- } \\
\text { treatment) }\end{array}$ & $\begin{array}{c}5 / 18 \\
(28 \%)[7]\end{array}$ & $\begin{array}{c}5 / 22(23 \%)[7] \\
4 / 21(19 \%)[50] \\
3 / 6(50 \%)[52] \\
5 / 10(50 \%)[53]\end{array}$ & $\begin{array}{c}3 / 10(30 \%)[7] \\
* 4 / 19(21 \%)[50] \\
* 33 / 55(60 \%)[54] \\
* 7 / 27(26 \%)[55] \\
1 / 2(50 \%)[53]\end{array}$ & $\begin{array}{c}59 / 267(22 \%)[56] \\
7 / 35(20 \%)[57] \\
28 / 147(19 \%)[58] \\
12 / 97(12 \%)[59] \\
16 / 103(16 \%)[60] \\
191 / 1107(17 \%)[61]\end{array}$ & $\begin{array}{c}16 / 131 \\
(12 \%)[62]\end{array}$ & $\begin{array}{c}* 30 / 104(29 \%)[54] \\
* 15 / 77(20 \%)[55] \\
* 49 / 233(21 \%)[56] \\
* 3 / 35(9 \%)[57] \\
* 17 / 164(10 \%)[58] \\
* 9 / 98(9 \%)[59] \\
* 19 / 103(18 \%)[60] \\
* 213 / 1312(16 \%)[61] \\
13 / 160(8 \%)[62]\end{array}$ \\
\hline Total & $\begin{array}{l}5 / 18 \\
(28 \%)\end{array}$ & $17 / 59(29 \%)$ & $48 / 113(42 \%)$ & $313 / 1756(18 \%)$ & $\begin{array}{c}16 / 131 \\
(12 \%)\end{array}$ & $368 / 2286(16 \%)$ \\
\hline $\begin{array}{l}\text { ICH (post- } \\
\text { treatment) }\end{array}$ & $\begin{array}{c}11 / 18 \\
(61 \%)[7]\end{array}$ & $\begin{array}{c}0 / 22(0 \%)[7] \\
3 / 17(18 \%)[50] \\
0 / 6(0 \%)[52] \\
4 / 10(40 \%)[53]\end{array}$ & $\begin{array}{c}4 / 10(40 \%)[7] \\
* 12 / 19(63 \%)[50] \\
* 44 / 222(20 \%)[51] \\
* 17 / 55(31 \%)[54] \\
* 10 / 25 \\
(40 \%)[55] \\
2 / 2(100 \%)[53]\end{array}$ & $\begin{array}{c}17 / 267(6 \%)(\mathrm{sICH})[56] \\
2 / 35(6 \%)(\mathrm{sICH})[57] \\
4 / 150(3 \%)(\mathrm{sICH})[58] \\
53 / 1110(5 \%)(\mathrm{sICH}) \\
{[61]}\end{array}$ & No studies & $\begin{array}{c}* 8730 / 134,048(7 \%)[51] \\
* 22 / 104(21 \%)[54] \\
* 38 / 77(49 \%)[55] \\
* 18 / 233(8 \%)(\mathrm{sICH})[56] \\
* 0 / 35(0 \%)(\mathrm{sICH})[57] \\
* 6 / 165(4 \%)(\mathrm{sICH})[58] \\
* 66 / 1313(5 \%)(\mathrm{sICH})[61]\end{array}$ \\
\hline Total & $\begin{array}{l}11 / 18 \\
(61 \%)\end{array}$ & $7 / 55(13 \%)$ & $89 / 333(27 \%)$ & $76 / 1562(5 \%)$ & $\mathrm{N} / \mathrm{A}$ & $8880 / 135,975(7 \%)$ \\
\hline $\begin{array}{l}\text { Reperfusion } \\
\text { Status (mTICI } \\
\text { 2b-3) }\end{array}$ & $\mathrm{N} / \mathrm{A}$ & $\begin{array}{c}5 / 6(83 \%)[52] \\
4 / 10(40 \%)[53]\end{array}$ & $\begin{array}{c}* 41 / 55(75 \%)[54] \\
* 24 / 28(86 \%)[55] \\
2 / 2(100 \%)[53]\end{array}$ & $\mathrm{N} / \mathrm{A}$ & No studies & $\begin{array}{c}* 91 / 104(88 \%)[54] \\
* 80 / 84(95 \%)[55] \\
* 115 / 196(59 \%)[56] \\
* 25 / 29(86 \%)[57] \\
* 113 / 156(72 \%)[58] \\
* 73 / 83(88 \%)[59] \\
* 67 / 102(66 \%)[60]\end{array}$ \\
\hline Total & N/A & $9 / 16(56 \%)$ & $30 / 85(35 \%)$ & $\mathrm{N} / \mathrm{A}$ & $\mathrm{N} / \mathrm{A}$ & $564 / 754(75 \%)$ \\
\hline $\begin{array}{l}\text { Good } \\
\text { Functional } \\
\text { Outcome } \\
\text { (mRS 0-2 at } \\
\text { three-month } \\
\text { follow-up) }\end{array}$ & $\begin{array}{c}7 / 17 \\
(41 \%)[7]\end{array}$ & $\begin{array}{c}15 / 22(68 \%)[7] \\
13 / 21 \\
(62 \%)[50] \\
3 / 6(50 \%)[52] \\
3 / 10(30 \%)[53]\end{array}$ & $\begin{array}{c}* 23 / 222(10 \%) \\
\text { (discharge into home } \\
\text { or self-care) [51] } \\
6 / 10(60 \%)[7] \\
* 7 / 19(37 \%)[50] \\
* 11 / 55(20 \%)[54] \\
* 7 / 27(26 \%)[55] \\
1 / 2(50 \%)[53]\end{array}$ & $\begin{array}{c}51 / 267(1 \%)[56] \\
14 / 35(40 \%)[57] \\
43 / 147(29 \%)[58] \\
33 / 93(35 \%)[59] \\
29 / 103(28 \%)[60] \\
351 / 1107(32 \%)[61]\end{array}$ & $\begin{array}{c}61 / 128 \\
(48 \%)[62]\end{array}$ & $\begin{array}{c}* 49,572 / 134,048(37 \%) \\
\text { (discharge into home or } \\
\text { self-care) [51] } \\
* 45 / 104(43 \%)[54] \\
* 39 / 77(51 \%)[55] \\
* 76 / 233(33 \%)[56] \\
* 25 / 35(71 \%)[57] \\
* 87 / 164(53 \%)[58] \\
* 59 / 98(60 \%)[59] \\
* 45 / 103(44 \%)[60] \\
* 557 / 1312(42 \%)[61] \\
90 / 156(58 \%)[62]\end{array}$ \\
\hline Total & $\begin{array}{l}7 / 17 \\
(41 \%)\end{array}$ & $34 / 59(58 \%)$ & $55 / 335(16 \%)$ & $521 / 1752(30 \%)$ & $\begin{array}{c}61 / 128 \\
(48 \%)\end{array}$ & $50,595 / 136,330(37 \%)$ \\
\hline
\end{tabular}

Abbreviations: AIS: acute ischaemic stroke; IE: infective endocarditis; mRS: modified Rankin Score; IVT: intravenous thrombolysis; EVT: endovascular thrombectomy; sICH: symptomatic intracerebral haemorrhage; N/A: not applicable. * Outcome results were not segregated by treatment group. Ref. [7]: Systematic review comparing IVT alone and EVT alone and EVT + IVT in AIS secondary to IE. However, combined treatment results from this study are not included in the table. Ref. [50]: Systematic review comparing IVT \pm EVT to EVT alone in AIS secondary to IE. However, out of the 19 patients in the IVT \pm EVT cohort, 18 received IVT only. Ref. [51]: Compared 222 AIS secondary to IE patients with 134,048 AIS patients without IE. All patients received IVT with 15 IE and 8263 non-IE patients receiving EVT as well. Ref. [52]: Case series analysing outcomes of 6 patients receiving EVT only in AIS secondary to IE. Ref. [54]: Compared 55 AIS secondary to IE patients with 104 AIS secondary to AF patients. All patients received EVT with 8 IE and 38 AF patients receiving IVT as well. Ref. [55]: Compared 28 AIS secondary to IE patients with 84 AIS secondary to AF patients. All patients received EVT with eight IE and $24 \mathrm{AF}$ patients receiving IVT as well. Ref. [53]: Case series of 12 patients experiencing AIS secondary to IE, with 10 patients receiving EVT only and two patients receiving EVT + IVT. Refs. [56-60]: These trials compared EVT \pm IVT against the control of usual care (e.g., IVT) in AIS patients. However, a minority of patients in the control group in all five studies did not receive IVT. However, outcome results were not segregated for these patients and were still presented as percentages of the total number of patients in the control groups. Also, all patients in the study group received EVT but not all received IVT, but outcome results were not segregated by treatment groups for these patients. Ref. [61]: Systematic review and meta-analysis of seven studies comparing EVT \pm IVT against the control of usual care (e.g., IVT) in AIS patients. However, a minority of patients in the control group did not receive IVT. Five of the seven studies are [56-60]. Ref. [62]: A pooled analysis of studies comparing EVT + IVT with EVT alone in AIS patients. 
In the following subsections, the majority of outcomes are obtained from Feil et al. [54] and Marnat et al.'s [55] retrospective observational studies. These are the two largest studies investigating outcomes of AIS in IE post-thrombectomy, which is the first-line treatment method due to IVT being contraindicated (if IE diagnosis is known). Furthermore, both studies compared outcomes of AIS secondary to IE with outcomes of AIS secondary to atrial fibrillation (AF) due to AF being the typical model for cardioembolic AIS with the majority of cardioembolic AIS occurring secondary to AF. However, differential rates of good functional outcomes, mortality and ICH occurrence corresponding to EVT/IVT alone, or combined treatment (EVT + IVT) groups were not reported. Further research into outcomes segregated by treatment groups and various IE aetiological factors is necessitated.

\section{Association with Good Functional Outcomes}

IE patients experiencing AIS were less likely to achieve good functional outcomes post-IVT and/or EVT than AIS patients without IE [51,54]. The retrospective analysis of a nationwide inpatient database found $10 \%$ of IE patients experiencing AIS achieved a good functional outcome compared to $37 \%$ of AIS patients without IE. However, this study defined good functional outcome as discharge into home or self-care rather than utilising the $\mathrm{mRS}$ score [51]. A retrospective analysis comparing two different cardioembolic aetiologies of AIS found $25.9 \%$ of IE patients achieved a good functional outcome (mRS 0-2) compared to $50.6 \%$ of the atrial fibrillation cohort [55]. This study had a relatively small sample size with only 28 IE patients and introduced possible bias by matching each IE patient with three AF patients [55]. However, comparable results were reported in a separate similar comparative analysis, with $20 \%$ of patients experiencing AIS secondary to IE achieving a good functional outcome (mRS 0-2) compared to $43.3 \%$ of the AF cohort experiencing AIS [54]. Furthermore, this multicentre study had the largest sample size of IE patients experiencing AIS receiving EVT to date [54].

\section{Association with Mortality}

Previous studies have found higher mortality rates in IE patients experiencing AIS than other AIS patients [54]. A retrospective study on patients experiencing AIS secondary to either IE or AF found no significant difference in mortality rate [55]. In contrast, another similar study on a relatively larger study population found a significantly higher mortality rate at the three-month follow-up in the IE cohort $(60 \%)$ compared to the AF cohort (28.8\%). However, the cause of mortality was not specified and thus it was unknown whether the death occurred due to stroke or underlying disease (IE). Furthermore, IE patients had poor comorbidity profiles, possibly influencing mortality rates. The causative pathogen for IE and affected heart valves were only known in $25.4 \%$ of patients in the study. Given IE is a heterogeneous disease with varying clinical outcomes dependent on the pathogen and valve affected [54], impact on mortality due to these factors alongside severity of stroke merits further research.

\section{Association with Adverse Events}

\subsection{Intracranial Haemorrhage}

IE patients experiencing AIS are associated with higher rates of ICH [51,54]. A nationwide retrospective study of AIS patients reported a post-IVT ICH rate of $19.8 \%$ in the IE cohort compared to only $6.5 \%$ in patients without IE [51]. However, due to recruiting patients from a database, ICH was classified using codes and severity was unable to be ascertained and categorized [51]. Another study found no difference in ICH occurrence rate between the IE and non-IE (AF) AIS cohorts [55]. However, whilst the rate of symptomatic ICH (sICH) was higher in the IE cohort, due to the small number of patients (six) experiencing an sICH, any statistical analysis was not possible. Further, due to the small sample size and a low number of patients receiving IVT, the influence of IVT on ICH in the IE cohort was unable to be determined [55]. A prospective case series found $50 \%$ of IE patients experiencing AIS and treated with EVT with or without IVT experienced HT, how- 
ever, this study included a small sample size of only 12 patients. Both patients receiving IVT experienced HT whilst of the three patients experiencing sICH, all three died by the three-month follow-up [53]. Similarly, in a matched control-case analysis of AIS secondary to IE or AF, $30.9 \%$ of the IE cohort experienced an ICH (determined in post-intervention imaging), compared to only $21.2 \%$ in the AF cohort [54]. However, detailed radiological or clinical descriptions of the ICH were not provided [54].

\subsection{Recurrent Stroke}

Previous studies suggest IE patients presenting with AIS are at higher risk of recurrent stroke. A retrospective study comparing IE and AF cohorts found $25 \%$ of the IE cohort experienced a recurrent stroke within three months, whilst no patients in the AF cohort had a recurrent stroke in that time period [55]. Whilst there was a small sample size, the control cohort was matched using major confounders and had similar early neurological conditions, thus suggesting IE may delay systemic complications and be associated with worse clinical outcomes. Despite matching on major confounders, $42.9 \%$ of the IE cohort had a pre-stroke mRS greater than or equal to 1 compared to only $17.9 \%$ of the AF cohort, suggesting possible selection bias in these results [55]. These findings have supported another study, with significantly higher rates of recurrent stroke during their hospital stay in the IE cohort $(12.7 \%)$ compared to the AF cohort (3.8\%) $(p=0.036)$ [54]. Although there was no significant difference in pre-stroke mRS between the two cohorts, differing lengths of hospital stays or differing severity of strokes could confound the association with recurrent stroke.

\subsection{Association with Successful Reperfusion}

Previous studies have reported greater rates of successful reperfusion defined by a modified Thrombolysis in Cerebral Infarction (mTICI) score between 2b-3 in AIS patients without IE than with IE [54,55]. A retrospective analysis comparing IE and AF cohorts experiencing AIS found $85.7 \%$ of the IE cohort achieved successful reperfusion post-EVT with or without IVT [55], compared to $95.2 \%$ of the AF cohort. However, this difference was not statistically significant $(p=0.11$ ). Near-complete reperfusion (mTICI $2 c-3$ ) was achieved in $71.4 \%$ of the IE cohort relative to $88.1 \%$ in the AF cohort $(p=0.014)$. Similar procedural times and complication rates indicated similar reperfusion success levels between the two cohorts [55]. Another retrospective study reported successful reperfusion in $74.5 \%$ of the IE cohort compared to $87.5 \%$ of the AF cohort $(p=0.039)$ [54]. However, differential rates of successful reperfusion corresponding to the EVT alone, or combined treatment $($ EVT + IVT) groups were not reported. Future studies investigating the reperfusion success among treatment groups would provide insights on the comparative efficacy of the treatments in IE patients.

\section{Stroke Prevention in IE}

Acute ischaemic stroke is a common complication of IE [7]. The key treatment strategy involves early antibiotic treatment to reduce secondary stroke risk. AIS secondary to IE is associated with an increased risk of mortality and morbidity. Previous retrospective studies have reported worse outcomes in AIS secondary to IE relative to other aetiologies. Acute treatment centres around the administration of IVT and/or EVT, however, the safety and efficacy of these methods are undetermined through existing studies. Currently, in AIS patients with suspected IE, IVT is not indicated. The evidence supporting EVT in such patients is also sub-optimal and incidents of haemorrhages, some multifocal, have been reported. In select cases of IE patients with TIA or AIS, early valve replacement should be considered. Antibiotic treatment is also recommended in IE patients with unruptured mycotic aneurysms, though neurosurgical consultation may be desirable in select patients with growing ruptured/unruptured mycotic aneurysms despite antibiotic therapy.

Antibiotic therapy should be initiated as soon as blood cultures are drawn in suspected or confirmed IE cases. The duration of the antibiotic regimen is determined based on the cause of the IE and valve affected. For example, whilst the treatment duration of six weeks 
is recommended for prosthetic valve IE patients; it is variable in native valve IE from two weeks (in uncomplicated IE due to common bacterial infections) to six weeks (enterococcal IE), respectively. Antibiotic therapy, especially early regimen, in IE is associated with a significant reduction in the risk of primary and secondary AIS. A large multicentric, multinational prospective cohort study of 1437 left-sided IE patients revealed a dramatic reduction in the risk of stroke on initiating antibiotic therapy [63]. While promptly initiating empirical antibiotic treatment on a high suspicion of IE, the antimicrobial selection approach based on the sensitivity of the antibiotic to the specific microbial, once confirmed, is recommended [64]. Moreover, an interprofessional team approach in selecting optimal antibiotic regimens involving treating physicians/neurologists, nurses, primary care physicians and pharmacists is recommended [64].

Embolism is a potentially fatal complication of IE [65]. The risk of embolisation is apparently increased in patients with increasing vegetation size, especially in patients with mitral endocarditis and staphylococcal endocarditis [65]. Another important consideration akin to stroke prevention in IE patients is the use of anticoagulation or antiplatelet therapy. Anticoagulation is not recommended as a stroke prevention strategy in IE patients due to increased risk of neurological complications including fatal haemorrhage and anticoagulant therapy should be promptly discontinued until the septic stage of the IE is appropriately managed [32,66]. In patients requiring systemic anticoagulation, the recommendation from the European Society of Cardiology is to pause anticoagulation for a minimum of 14 days for IE patients on an antibiotic regimen (low level of evidence) [67]. Should anticoagulation be necessary, oral anticoagulation may be replaced with heparin for two weeks in IE cases presenting with AIS. Consistent with indication against anticoagulation in IE patients, antiplatelet therapy is also not indicated in reducing the risk of embolism towards early management of IE patients [68], due to increased bleeding or haemorrhage risks [69]. An RCT examining the effect of aspirin in IE patients already on antibiotic therapy, on the risk of embolic events in IE reported an increased risk of bleeding [69]. However, a retrospective study reported a reduction in symptomatic emboli associated with IE in patients on continuous daily prior antiplatelet therapy for a minimum of 6 months prior to IE related hospitalization [70]. Moreover, while there is an indication in favour of cardiac valve replacement surgery in preventing embolism during the first week of antibiotic therapy, its exact role in mitigating embolism is still debatable [67].

\section{Conclusions}

In conclusion, the management of AIS patients with presumed or confirmed IE is challenging and treatment guidelines are far from optimal due to limited evidence. High-quality evidence, drawn from large cohort studies and/or randomised control trials investigating the outcomes of EVT as compared to IVT or combination therapy in AIS secondary to IE, is needed. Future studies investigating the role of baseline clinical or imaging factors in determining prognosis in IE patients after AIS is also warranted.

Author Contributions: S.M.M.B. conceived the study, contributed to the planning, draft, and revision of the manuscript, supervision of the student. S.M.M.B. encouraged R.M. to investigate and supervised the findings of this work. S.M.M.B. and R.M. wrote the first draft of this paper. D.W. and D.J.C. contributed to the writing and critical revision of the manuscript. All authors contributed to the revision of the manuscript. All authors have read and agreed to the published version of the manuscript.

Funding: Funding for the NSW Brain Clot Bank (Chief Investigator: Bhaskar) from the NSW Ministry of Health (2019-2022) is acknowledged. The funding body has no role in the study design, data collection, analysis, interpretation of findings and manuscript preparation. The content is solely the responsibility of the authors and does not necessarily represent the official views of the affiliated/funding organization/s.

Data Availability Statement: The original contributions presented in the study are included in the article. Further inquiries can be directed to the corresponding author. 
Conflicts of Interest: The authors declare that they have no conflict of interest.

\section{References}

1. Campbell, B.C.; De Silva, D.A.; Macleod, M.R.; Coutts, S.B.; Schwamm, L.H.; Davis, S.M.; Donnan, G.A. Ischaemic stroke. Nat. Rev. Dis. Primers 2019, 5, 70. [CrossRef]

2. Sonneville, R.; Mourvillier, B.; Bouadma, L.; Wolff, M. Management of neurological complications of infective endocarditis in ICU patients. Ann. Intensive Care 2011, 1, 10. [CrossRef] [PubMed]

3. Chen, C.-C.; Wu, V.C.-C.; Chang, C.-H.; Chen, C.-T.; Hsieh, P.-C.; Liu, Z.-H.; Wong, H.-F.; Yang, C.-H.; Chou, A.-H.; Chu, P.-H. Long-term outcome of neurological complications after infective endocarditis. Sci. Rep. 2020, 10, 3994. [CrossRef] [PubMed]

4. Pruitt, A.; Rubin, R.H.; Karchmer, A.; Duncan, G.W. Neurologic complications of bacterial endocarditis. Medicine 1978, 57, 329-343. [CrossRef] [PubMed]

5. Forestier, E.; Fraisse, T.; Roubaud-Baudron, C.; Selton-Suty, C.; Pagani, L. Managing infective endocarditis in the elderly: New issues for an old disease. Clin. Interv. Aging 2016, 11, 1199-1206. [CrossRef] [PubMed]

6. Durante-Mangoni, E.; Bradley, S.; Selton-Suty, C.; Tripodi, M.F.; Barsic, B.; Bouza, E.; Cabell, C.H.; Ramos, A.I.; Fowler, V., Jr.; Hoen, B.; et al. Current features of infective endocarditis in elderly patients: Results of the International Collaboration on Endocarditis Prospective Cohort Study. Arch. Intern. Med. 2008, 168, 2095-2103. [CrossRef] [PubMed]

7. Bettencourt, S.; Ferro, J.M. Acute ischemic stroke treatment in infective endocarditis: Systematic review. J. Stroke Cerebrovasc. Dis. 2020, 29, 104598. [CrossRef]

8. Bhaskar, S.; Cordato, D.; Cappelen-Smith, C.; Cheung, A.; Ledingham, D.; Celermajer, D.; Levi, C. Clarion call for histopathological clot analysis in "cryptogenic" ischemic stroke: Implications for diagnosis and treatment. Ann. Clin. Transl. Neurol. 2017, 4, 926-930. [CrossRef]

9. $\quad$ Bhaskar, S.; Saab, J.; Cappelen-Smith, C.; Killingsworth, M.; Wu, X.J.; Cheung, A.; Manning, N.; Aouad, P.; McDougall, A.; Hodgkinson, S.; et al. Clot Histopathology in Ischemic Stroke with Infective Endocarditis. Can. J. Neurol. Sci. 2019, 46, 331-336. [CrossRef]

10. Abdulhak, A.A.B.; Baddour, L.M.; Erwin, P.J.; Hoen, B.; Chu, V.H.; Mensah, G.A.; Tleyjeh, I.M. Global and regional burden of infective endocarditis, 1990-2010: A systematic review of the literature. Glob. Heart 2014, 9, 131-143. [CrossRef]

11. Ambrosioni, J.; Hernandez-Meneses, M.; Téllez, A.; Pericàs, J.; Falces, C.; Tolosana, J.; Vidal, B.; Almela, M.; Quintana, E.; Llopis, J. The changing epidemiology of infective endocarditis in the twenty-first century. Curr. Infect. Dis. Rep. 2017, 19, 21. [CrossRef]

12. Sy, R.W.; Kritharides, L. Health care exposure and age in infective endocarditis: Results of a contemporary population-based profile of 1536 patients in Australia. Eur. Heart J. 2010, 31, 1890-1897. [CrossRef]

13. Xu, H.; Cai, S.; Dai, H. Characteristics of infective endocarditis in a tertiary hospital in East China. PLoS ONE 2016, 11, e0166764. [CrossRef]

14. Letaief, A.; Boughzala, E.; Kaabia, N.; Ernez, S.; Abid, F.; Chaabane, T.B.; Jemaa, M.B.; Boujnah, R.; Chakroun, M.; Daoud, M. Epidemiology of infective endocarditis in Tunisia: A 10-year multicenter retrospective study. Int. J. Infect. Dis. 2007, 11, 430-433. [CrossRef] [PubMed]

15. Ferreiros, E.; Nacinovich, F.; Casabé, J.H.; Modenesi, J.C.; Swieszkowski, S.; Cortes, C.; Hernan, C.A.; Kazelian, L.; Varini, S. Epidemiologic, clinical, and microbiologic profile of infective endocarditis in Argentina: A national survey. The Endocarditis Infecciosa en la República Argentina-2 (EIRA-2) Study. Am. Heart J. 2006, 151, 545-552. [CrossRef] [PubMed]

16. Salvador, V.B.D.; Chapagain, B.; Joshi, A.; Brennessel, D.J. Clinical risk factors for infective endocarditis in Staphylococcus aureus bacteremia. Tex. Heart Inst. J. 2017, 44, 10-15. [CrossRef] [PubMed]

17. Murdoch, D.R.; Corey, G.R.; Hoen, B.; Miró, J.M.; Fowler, V.G.; Bayer, A.S.; Karchmer, A.W.; Olaison, L.; Pappas, P.A.; Moreillon, P. Clinical presentation, etiology, and outcome of infective endocarditis in the 21st century: The International Collaboration on Endocarditis-Prospective Cohort Study. Arch. Intern. Med. 2009, 169, 463-473. [CrossRef]

18. Habib, G.; Erba, P.A.; Iung, B.; Donal, E.; Cosyns, B.; Laroche, C.; Popescu, B.A.; Prendergast, B.; Tornos, P.; Sadeghpour, A. Clinical presentation, aetiology and outcome of infective endocarditis. Results of the ESC-EORP EURO-ENDO (European infective endocarditis) registry: A prospective cohort study. Eur. Heart J. 2019, 40, 3222-3232. [CrossRef]

19. Keynan, Y.; Rubinstein, E. Pathophysiology of infective endocarditis. Curr. Infect. Dis. Rep. 2013, 15, 342-346. [CrossRef] [PubMed]

20. Feigin, V.L.; Barker-Collo, S.; Krishnamurthi, R.; Theadom, A.; Starkey, N. Epidemiology of ischaemic stroke and traumatic brain injury. Best Pract. Res. Clin. Anaesthesiol. 2010, 24, 485-494. [CrossRef]

21. Feigin, V.L.; Krishnamurthi, R.V.; Parmar, P.; Norrving, B.; Mensah, G.A.; Bennett, D.A.; Barker-Collo, S.; Moran, A.E.; Sacco, R.L.; Truelsen, T.; et al. Update on the global burden of ischemic and hemorrhagic stroke in 1990-2013: The GBD 2013 study. Neuroepidemiology 2015, 45, 161-176. [CrossRef] [PubMed]

22. Guo, Y.; Li, P.; Guo, Q.; Shang, K.; Yan, D.; Du, S.; Lu, Y. Pathophysiology and biomarkers in acute ischemic stroke-a review. Trop. J. Pharm. Res. 2013, 12, 1097-1105. [CrossRef]

23. Moustafa, R.R.; Baron, J.C. Pathophysiology of ischaemic stroke: Insights from imaging, and implications for therapy and drug discovery. Br. J. Pharmacol. 2008, 153, S44-S54. [CrossRef] [PubMed]

24. Ferro, J.M.; Massaro, A.R.; Mas, J.-L. Aetiological diagnosis of ischaemic stroke in young adults. Lancet Neurol. 2010, 9, 1085-1096. [CrossRef] 
25. Heiro, M.; Nikoskelainen, J.; Engblom, E.; Kotilainen, E.; Marttila, R.; Kotilainen, P. Neurologic manifestations of infective endocarditis: A 17-year experience in a teaching hospital in Finland. Arch. Intern. Med. 2000, 160, 2781-2787. [CrossRef] [PubMed]

26. Ruttmann, E.; Willeit, J.; Ulmer, H.; Chevtchik, O.; Höfer, D.; Poewe, W.; Laufer, G.; Müller, L.C. Neurological Outcome of Septic Cardioembolic Stroke After Infective Endocarditis. Stroke 2006, 37, 2094-2099. [CrossRef] [PubMed]

27. Karchmer, A. Infective Endocarditis. Braunwald's Heart Disease: A Textbook of Cardiovascular Medicine, 7th ed.; WB Saunders: Philadelphia, PA, USA, 2005.

28. Guzek, A.; Braksator, W.; Gąsior, Z.; Kuśmierczyk, M.; Różański, J.; Rybicki, Z. Infective endocarditis-can we treat it more effectively? Kardiochir. Torakochir. Pol. 2020, 17, 8-14. [CrossRef] [PubMed]

29. Brusch, J.L. Infective Endocarditis. Available online: https://emedicine.medscape.com/article/216650-overview\#showall (accessed on 12 September 2021).

30. Morris, N.A.; Matiello, M.; Lyons, J.L.; Samuels, M.A. Neurologic complications in infective endocarditis: Identification, management, and impact on cardiac surgery. Neurohospitalist 2014, 4, 213-222. [CrossRef]

31. Kamel, H.; Healey, J.S. Cardioembolic stroke. Circ. Res. 2017, 120, 514-526. [CrossRef]

32. García-Cabrera, E.; Fernández-Hidalgo, N.; Almirante, B.; Ivanova-Georgieva, R.; Noureddine, M.; Plata, A.; Lomas, J.M.; Gálvez-Acebal, J.; Hidalgo-Tenorio, C.; Ruíz-Morales, J.; et al. Neurological complications of infective endocarditis: Risk factors, outcome, and impact of cardiac surgery: A multicenter observational study. Circulation 2013, 127, 2272-2284. [CrossRef]

33. Valenzuela, I.; Hunter, M.D.; Sundheim, K.; Klein, B.; Dunn, L.; Sorabella, R.; Han, S.M.; Willey, J.; George, I.; Gutierrez, J. Clinical risk factors for acute ischaemic and haemorrhagic stroke in patients with infective endocarditis. Intern. Med. J. 2018, 48, 1072-1080. [CrossRef]

34. Schirone, L.; Iaccarino, A.; Saade, W.; D’Abramo, M.; De Bellis, A.; Frati, G.; Sciarretta, S.; Mestres, C.-A.; Greco, E. Cerebrovascular complications and infective endocarditis: Impact of available evidence on clinical outcome. BioMed Res. Int. 2018, 2018, 4109358. [CrossRef]

35. Deprele, C.; Berthelot, P.; Lemetayer, F.; Comtet, C.; Fresard, A.; Cazorla, C.; Fascia, P.; Cathébras, P.; Chaumentin, G.; Convert, G. Risk factors for systemic emboli in infective endocarditis. Clin. Microbiol. Infect. 2004, 10, 46-53. [CrossRef] [PubMed]

36. Grecu, N.; Cristina, T.; Terecoasa, E.; Bajenaru, O. Endocarditis and stroke. Maedica 2014, 9, 375.

37. Kang, D.-H.; Kim, Y.-J.; Kim, S.-H.; Sun, B.J.; Kim, D.-H.; Yun, S.-C.; Song, J.-M.; Choo, S.J.; Chung, C.-H.; Song, J.-K.; et al. Early surgery versus conventional treatment for infective endocarditis. N. Engl. J. Med. 2012, 366, 2466-2473. [CrossRef] [PubMed]

38. Thuny, F.; Avierinos, J.-F.; Tribouilloy, C.; Giorgi, R.; Casalta, J.-P.; Milandre, L.; Brahim, A.; Nadji, G.; Riberi, A.; Collart, F.; et al. Impact of cerebrovascular complications on mortality and neurologic outcome during infective endocarditis: A prospective multicentre study. Eur. Heart J. 2007, 28, 1155-1161. [CrossRef] [PubMed]

39. Jauch, E.C.; Saver, J.L.; Adams, H.P., Jr.; Bruno, A.; Connors, J.; Demaerschalk, B.M.; Khatri, P.; McMullan, P.W., Jr.; Qureshi, A.I.; Rosenfield, K. Guidelines for the early management of patients with acute ischemic stroke: A guideline for healthcare professionals from the American Heart Association/American Stroke Association. Stroke 2013, 44, 870-947. [CrossRef] [PubMed]

40. Ravindran, A.V.; Killingsworth, M.C.; Bhaskar, S. Cerebral collaterals in acute ischaemia: Implications for acute ischaemic stroke patients receiving reperfusion therapy. Eur. J. Neurosci. 2021, 53, 1238-1261. [CrossRef]

41. Rastogi, A.; Weissert, R.; Bhaskar, S.M.M. Emerging role of white matter lesions in cerebrovascular disease. Eur. J. Neurosci. 2021, 54, 5531-5559. [CrossRef]

42. Rastogi, A.; Weissert, R.; Bhaskar, S.M.M. Leukoaraiosis severity and post-reperfusion outcomes in acute ischaemic stroke: A meta-analysis. Acta Neurol. Scand. 2021. [CrossRef]

43. Shi, C.; Killingsworth, M.C.; Bhaskar, S.M.M. Prognostic capacity of hyperdense middle cerebral artery sign in anterior circulation acute ischaemic stroke patients receiving reperfusion therapy: A systematic review and meta-analysis. Acta Neurol. Belg. 2021, 1-13. [CrossRef]

44. Baskar, P.S.; Chowdhury, S.Z.; Bhaskar, S.M.M. In-hospital systems interventions in acute stroke reperfusion therapy: A metaanalysis. Acta Neurol. Scand. 2021, 144, 418-432. [CrossRef] [PubMed]

45. Santana Baskar, P.; Cordato, D.; Wardman, D.; Bhaskar, S. In-hospital acute stroke workflow in acute stroke-Systems-based approaches. Acta Neurol. Scand. 2021, 143, 111-120. [CrossRef]

46. Venkat, A.; Cappelen-Smith, C.; Askar, S.; Thomas, P.R.; Bhaskar, S.; Tam, A.; McDougall, A.J.; Hodgkinson, S.J.; Cordato, D.J. Factors Associated with Stroke Misdiagnosis in the Emergency Department: A Retrospective Case-Control Study. Neuroepidemiology 2018, 51, 123-127. [CrossRef] [PubMed]

47. Bhaskar, S.; Bivard, A.; Stanwell, P.; Parsons, M.; Attia, J.R.; Nilsson, M.; Levi, C. Baseline collateral status and infarct topography in post-ischaemic perilesional hyperperfusion: An arterial spin labelling study. J. Cereb. Blood Flow Metab. 2017, 37, 1148-1162. [CrossRef] [PubMed]

48. Gariel, F.; Lapergue, B.; Bourcier, R.; Berge, J.; Barreau, X.; Mazighi, M.; Kyheng, M.; Labreuche, J.; Fahed, R.; Blanc, R. Mechanical thrombectomy outcomes with or without intravenous thrombolysis: Insight from the ASTER randomized trial. Stroke 2018, 49, 2383-2390. [CrossRef]

49. D'Anna, L. Endovascular treatment of ischemic large-vessel stroke due to infective endocarditis: Case series and review of the literature. Neurol. Sci. 2020, 41, 3517-3525. [CrossRef]

50. Marquardt, R.J.; Cho, S.-M.; Thatikunta, P.; Deshpande, A.; Wisco, D.; Uchino, K. Acute ischemic stroke therapy in infective endocarditis: Case series and systematic review. J. Stroke Cerebrovasc. Dis. 2019, 28, 2207-2212. [CrossRef] 
51. Asaithambi, G.; Adil, M.M.; Qureshi, A.I. Thrombolysis for ischemic stroke associated with infective endocarditis: Results from the nationwide inpatient sample. Stroke 2013, 44, 2917-2919. [CrossRef] [PubMed]

52. Ambrosioni, J.; Urra, X.; Hernández-Meneses, M.; Almela, M.; Falces, C.; Tellez, A.; Quintana, E.; Fuster, D.; Sandoval, E.; Vidal, B. Mechanical thrombectomy for acute ischemic stroke secondary to infective endocarditis. Clin. Infect. Dis. 2018, 66, 1286-1289. [CrossRef]

53. Ramos, C.; Mayo, P.; Trillo, S.; Gómez-Escalonilla, C.; Caniego, J.L.; Moreu, M.; Vega, J.; Rosati, S.; Simal, P.; Carrillo, Á.X. Management of Large Vessel Occlusion Stroke Related to Infective Endocarditis: Is Mechanical Thrombectomy a Safe Option? J. Stroke Cerebrovasc. Dis. 2020, 29, 105248. [CrossRef] [PubMed]

54. Feil, K.; Küpper, C.; Tiedt, S.; Dimitriadis, K.; Herzberg, M.; Dorn, F.; Liebig, T.; Dieterich, M.; Kellert, L.; for the GSR Investigators. Safety and efficacy of mechanical thrombectomy in infective endocarditis: A matched case-control analysis from the German Stroke Registry-Endovascular Treatment. Eur. J. Neurol. 2021, 28, 861-867. [CrossRef] [PubMed]

55. Marnat, G.; Sibon, I.; Gory, B.; Richard, S.; Olindo, S.; Consoli, A.; Bourcier, R.; Kyheng, M.; Labreuche, J.; Darganzali, C. Safety and outcomes of mechanical thrombectomy for acute stroke related to infective endocarditis: A case-control study. Int. J. Stroke 2020, 16, 585-592. [CrossRef]

56. Berkhemer, O.A.; Fransen, P.S.; Beumer, D.; Van Den Berg, L.A.; Lingsma, H.F.; Yoo, A.J.; Schonewille, W.J.; Vos, J.A.; Nederkoorn, P.J.; Wermer, M.J.; et al. A randomized trial of intraarterial treatment for acute ischemic stroke. N. Engl. J. Med. 2015, 372, 11-20. [CrossRef] [PubMed]

57. Campbell, B.C.; Mitchell, P.J.; Kleinig, T.J.; Dewey, H.M.; Churilov, L.; Yassi, N.; Yan, B.; Dowling, R.J.; Parsons, M.W.; Oxley, T.J.; et al. Endovascular therapy for ischemic stroke with perfusion-imaging selection. N. Engl. J. Med. 2015, 372, 1009-1018. [CrossRef]

58. Goyal, M.; Demchuk, A.M.; Menon, B.K.; Eesa, M.; Rempel, J.L.; Thornton, J.; Roy, D.; Jovin, T.G.; Willinsky, R.A.; Sapkota, B.L.; et al. Randomized assessment of rapid endovascular treatment of ischemic stroke. N. Engl. J. Med. 2015, 372, 1019-1030. [CrossRef]

59. Saver, J.L.; Goyal, M.; Bonafe, A.; Diener, H.-C.; Levy, E.I.; Pereira, V.M.; Albers, G.W.; Cognard, C.; Cohen, D.J.; Hacke, W.; et al. Stent-retriever thrombectomy after intravenous t-PA vs. t-PA alone in stroke. N. Engl. J. Med. 2015, 372, 2285-2295. [CrossRef] [PubMed]

60. Jovin, T.G.; Chamorro, A.; Cobo, E.; de Miquel, M.A.; Molina, C.A.; Rovira, A.; San Román, L.; Serena, J.; Abilleira, S.; Ribó, M. Thrombectomy within 8 hours after symptom onset in ischemic stroke. N. Engl. J. Med. 2015, 372, 2296-2306. [CrossRef]

61. Sardar, P.; Chatterjee, S.; Giri, J.; Kundu, A.; Tandar, A.; Sen, P.; Nairooz, R.; Huston, J.; Ryan, J.J.; Bashir, R.; et al. Endovascular therapy for acute ischaemic stroke: A systematic review and meta-analysis of randomized trials. Eur. Heart J. 2015, 36, 2373-2380. [CrossRef]

62. Coutinho, J.M.; Liebeskind, D.S.; Slater, L.-A.; Nogueira, R.G.; Clark, W.; Dávalos, A.; Bonafé, A.; Jahan, R.; Fischer, U.; Gralla, J. Combined intravenous thrombolysis and thrombectomy vs thrombectomy alone for acute ischemic stroke: A pooled analysis of the SWIFT and STAR studies. JAMA Neurol. 2017, 74, 268-274. [CrossRef]

63. Dickerman, S.A.; Abrutyn, E.; Barsic, B.; Bouza, E.; Cecchi, E.; Moreno, A.; Doco-Lecompte, T.; Eisen, D.P.; Fortes, C.Q.; Fowler, V.G., Jr.; et al. The relationship between the initiation of antimicrobial therapy and the incidence of stroke in infective endocarditis: An analysis from the ICE Prospective Cohort Study (ICE-PCS). Am. Heart J. 2007, 154, 1086-1094. [CrossRef] [PubMed]

64. Tackling, G.; Lala, V. Endocarditis Antibiotic Regimens. [Updated 2021 April 21]. In StatPearls [Internet]; StatPearls Publishing: Treasure Island, FL, USA, 2021. Available online: https:/ / www.ncbi.nlm.nih.gov/books/NBK542162/ (accessed on 12 September 2021).

65. Vilacosta, I.; Graupner, C.; San Román, J.A.; Sarriá, C.; Ronderos, R.; Fernández, C.; Mancini, L.; Sanz, O.; Sanmartín, J.V.; Stoermann, W. Risk of embolization after institution of antibiotic therapy for infective endocarditis. J. Am. Coll. Cardiol. 2002, 39, 1489-1495. [CrossRef]

66. Tornos, P.; Almirante, B.; Mirabet, S.; Permanyer, G.; Pahissa, A.; Soler-Soler, J. Infective endocarditis due to Staphylococcus aureus: Deleterious effect of anticoagulant therapy. Arch. Intern. Med. 1999, 159, 473-475. [CrossRef] [PubMed]

67. Habib, G.; Hoen, B.; Tornos, P.; Thuny, F.; Prendergast, B.; Vilacosta, I.; Moreillon, P.; de Jesus Antunes, M.; Thilen, U.; Lekakis, J.; et al. Guidelines on the prevention, diagnosis, and treatment of infective endocarditis (new version 2009): The Task Force on the Prevention, Diagnosis, and Treatment of Infective Endocarditis of the European Society of Cardiology (ESC). Endorsed by the European Society of Clinical Microbiology and Infectious Diseases (ESCMID) and the International Society of Chemotherapy (ISC) for Infection and Cancer. Eur. Heart J. 2009, 30, 2369-2413. [CrossRef] [PubMed]

68. Hoen, B.; Duval, X. Infective Endocarditis. N. Engl. J. Med. 2013, 368, 1425-1433. [CrossRef]

69. Chan, K.L.; Dumesnil, J.G.; Cujec, B.; Sanfilippo, A.J.; Jue, J.; Turek, M.A.; Robinson, T.I.; Moher, D. A randomized trial of aspirin on the risk of embolic events in patients with infective endocarditis. J. Am. Coll. Cardiol. 2003, 42, 775-780. [CrossRef]

70. Anavekar, N.S.; Tleyjeh, I.M.; Anavekar, N.S.; Mirzoyev, Z.; Steckelberg, J.M.; Haddad, C.; Khandaker, M.H.; Wilson, W.R.; Chandrasekaran, K.; Baddour, L.M. Impact of prior antiplatelet therapy on risk of embolism in infective endocarditis. Clin. Infect. Dis. 2007, 44, 1180-1186. [CrossRef] 